\title{
Asia-Pacific Science Education (APSE): expanding opportunities for publishing science education research
}

Sonya N. Martin ${ }^{1 *}$ and Hye-Eun Chu ${ }^{2}$

\author{
* Correspondence: sonya.n.martin@ \\ gmail.com \\ ${ }^{1}$ Earth Science Education \\ Department, College of Education, \\ Seoul National University, Seoul, \\ Republic of Korea \\ Full list of author information is \\ available at the end of the article
}

We are pleased to introduce a new journal, Asia-Pacific Science Education, which was created to provide researchers in the Asia-Pacific region with a central channel for disseminating research in local contexts about issues in science education to both science educators in the geographical region and researchers in the extended international community. APSE is unique in that our journal focuses on the publication of scholarly articles examining issues related to science teaching and learning in Asia as well as articles that address the issues facing science teachers and science learners who are members of the Asian Diaspora. ${ }^{1}$ As a result, we expect the scholarly works published in APSE will encompass diverse topics of interest that will be significant for a wide readership.

In this introductory issue, we describe the origins of APSE and we share findings from an analysis of publication data from other major journals in the field that demonstrate a need for APSE. Next we share our vision for the role APSE can play in supporting the development of an academic community where studies conducted in the Asia-Pacific region and studies conducted with participants from the Asian Diaspora will be valued and accessed by scholars who are concerned about science education issues affecting these communities. We conclude by offering a detailed description of the unique features APSE offers our authors and readers, including a supportive peerreview process that is considerate of the challenges facing non-native English speakers. Finally, we explain how our open access (OA) publication model ensures that researchers and teachers anywhere in the world can access and read all content in our journal for free.

\section{Origins of APSE}

APSE is an international journal sponsored by the Korean Association for Science Education (KASE) and is published in collaboration with Springer. KASE was founded in 1976 (formerly known as the Korean Association for Research in Science Education) and currently has more than 3,500 members, both domestically and internationally. The purpose of KASE is to make contributions to the advancement of science education through research and development. To support these goals, the KASE organization sponsors two science education conferences a year and two journals, including APSE, to help disseminate research findings to researchers, teacher educators, and teacher practitioners. 
Since 1978, KASE has published the Journal of the Korean Association for Science Education (JKASE), beginning with only one issue every two years and then progressing to twice a year in 1984 (Park 1996). Currently, JKASE publishes eight issues a year and is recognized as the top journal in science education research in Korea (Song and Joung 2014). The leadership of KASE recognized the growing need for science educators in Korea to be able to share their research with an international audience while also needing a publishing venue for sharing innovations in science research and pedagogy domestically, so they began publishing two of their eight issues a year in English. Based on the success of the English language issues and the continued need for KASE members to publish their work so it would be accessible to a wider audience, KASE leaders decided to create an independent English language science education journal that could serve as a space for disseminating research internationally.

Thus, the impetus for this journal has developed over many years and is a culmination of the collaborative efforts of many different KASE leaders. The 14th president of KASE, Jong-Yoon Park, initiated early meetings with Springer in 2012 and oversaw the development of the internationalization committee. Over the next two years, President Youngmin Kim worked tirelessly to develop the infrastructure needed to support APSE within the KASE organization, collaborated with KASE membership to develop the scope and aims of the journal, and initiated the contract negotiations with Springer. These efforts were further supported and expanded by current KASE President Heui-Baik Kim, who has overseen the official establishment of APSE as a Springer journal and who has supported the editorial team to prepare this first issue. Their combined leadership and vision has brought to fruition the APSE journal, which is now poised to develop a strong community of science educators and researchers in Korea, in the Asia-Pacific region, and beyond.

APSE is headed by Jinwoong Song (Editor in Chief), Sonya Martin, Hye-Eun Chu, and Namhwa Kang (Co-Editors), and by Young-Shin Park (International Coordinator). All five of the leading members of APSE have worked and lived internationally (in England, USA, Singapore, and Australia) and domestically in Korea. In addition, all five are active members of KASE and have served in various leadership roles on editorial boards for other international and domestic academic journals. There are also four associate editors and 21 editorial board members from 12 different countries-including seven in the AsiaPacific region. Together we will work to establish APSE and develop a respected academic journal that is recognized for its high quality publications and a place for reading cuttingedge research. As the readership of APSE grows, we will be calling upon scholars in the region to join our editorial board so that we can expand our social networks in different regions and discipline areas so we can engage more scholars to share their work in APSE.

\section{Why is APSE necessary for our science education research community?}

Our experiences in academic publishing and as participants in international and regional research communities have made it clear to us there is an urgent need for APSE. In this section we use a simple analysis of publication trends in several leading science education journals to highlight how few individuals from institutions located in Asian countries have published in what are considered the top journals in the field of science education. In addition, we draw attention to how few of the papers that have been published in these journals actually focus on issues related to science teaching and learning in Asia or deal with participants representing members of the Asian Diaspora. 
Following methods similar to recently published studies examining the impact of English language use on publishing in science education journals (see Martin and Siry 2011) and other trends in publishing (Tsai 2005; Lee et al. 2009; Rollnick et al. 2009), we conducted an analysis of publications within the most recent five years (2010-2014) from four science education journals: the Journal of Research in Science Teaching (JRST), Science Education (SE), Research in Science Education (RISE), and the International Journal of Science Education (IJSE). We selected only those journals that are included in the Social Sciences Citation Index (SSCI) and excluded journals that were not solely focused on science education (meaning we did not include journals that feature research in math or technology education or the learning sciences). Using data from Journal Citation Reports (2014), we identified the impact factor rating and the relative rank of each journal in the Education and Educational Research category. All four journals are widely accessed by researchers in the field of science education and all four journals are published in English and are accessible in on-line formats as well as in print.

Our analysis included all editorials, book reviews, commentaries, and research papers, and we did not include articles printed by journal editors referencing corrections or errors in previous issues of the journal. We determined the total number of papers published for each journal per year and then identified the percentage of papers that included even one author from an institution located in a country in the Asia-Pacific region. Table 1 illustrates the findings from our analysis of all publications for these journals during the five-year period. Our analysis focused on identifying university affiliation and geographical location for each author. We included a paper for analysis if even one author, regardless of authorship position (i.e., lead author, last author, etc.), was affiliated with an institution in a country in the geographical Asia-Pacific region (including countries in Central and Southeast Asia). However, we did not count authors who were affiliated with institutions in countries where the majority of the inhabitants are not identified as racially/ethnically Asian. For example Australia, whose Asian population is less than $7 \%$ of the total population, was not considered to be an Asian country even though it can be argued that Australia is geographically located in the Asia-Pacific region. We also want to acknowledge that institutional affiliation does not necessarily correlate with the author's nationality or ethnicity. We were simply looking at representation based on author affiliation with institutions in Asian countries.

Our analysis revealed that out of a total of 1,309 publications, only 127 (9.7 \%) included authors representing an institution in an Asian country. Publications by researchers at institutions in Asian countries represented only 3-5\% of all publications over the five-year period in the top two most highly ranked journals (JRST and $S E$ )

Table 1 Comparison of journal rank and publications versus total number of Asian countries represented

\begin{tabular}{lcccc}
\hline Journal & $\begin{array}{l}\text { Rank in Education \& Educational } \\
\text { Research category (of 224) }\end{array}$ & $\begin{array}{l}\text { Impact } \\
\text { Factor (IF) } \\
\text { rating }\end{array}$ & $\begin{array}{l}\text { Total } \\
\text { publications } \\
(2010-2014)\end{array}$ & $\begin{array}{l}\text { Percentage of publications from } \\
\text { institutions in Asian countries }\end{array}$ \\
\hline JRST & 4 & 3.162 & 236 & 3.39 \\
SE & 7 & 2.825 & 205 & 4.88 \\
IJSE & 61 & 1.132 & 576 & 14.58 \\
RISE & 102 & 0.806 & 292 & 8.56 \\
\hline
\end{tabular}


in the field of science education. However, there was about greater representation (8-15\%) by authors from Asian countries in IJSE and RISE.

While both RISE and IJSE published a larger percentage of articles with authors from Asian countries (see Fig. 1), close examination revealed that the majority of publications including authors representing Asian countries were co-authored and the majority of the co-authors represented institutions in non-Asian countries, specifically countries where English is spoken as a native language (i.e., United States, England, and Australia). Only 12 of 127 (9.4\%) papers were single-authored by a researcher from an institution in Asia.

A more detailed analysis of the topics and issues addressed in 127 papers published with authors representing institutions in Asia found that about half of the publications were acontextual, meaning no context was provided about where the study took place or who the participants in the study were. Our analysis revealed studies focusing on assessment or conceptual/affective studies, which tend to be conventional research areas in science education, failed to discuss how the methods or findings were salient for science teaching and learning in Asian contexts. For these studies, that the research took place in educational contexts in Asian countries or that participants were identifiable as Asian or members of the Asian Diaspora was of no importance. For those publications that did address context, authors tended to focus on topics like curriculum, evaluation, and assessment, conceptual change research, or learning environments research. In these cases, the research was usually being reported as an international cross-comparative study rather than focusing solely on issues relevant to or descriptive about science education issues a particular local context.

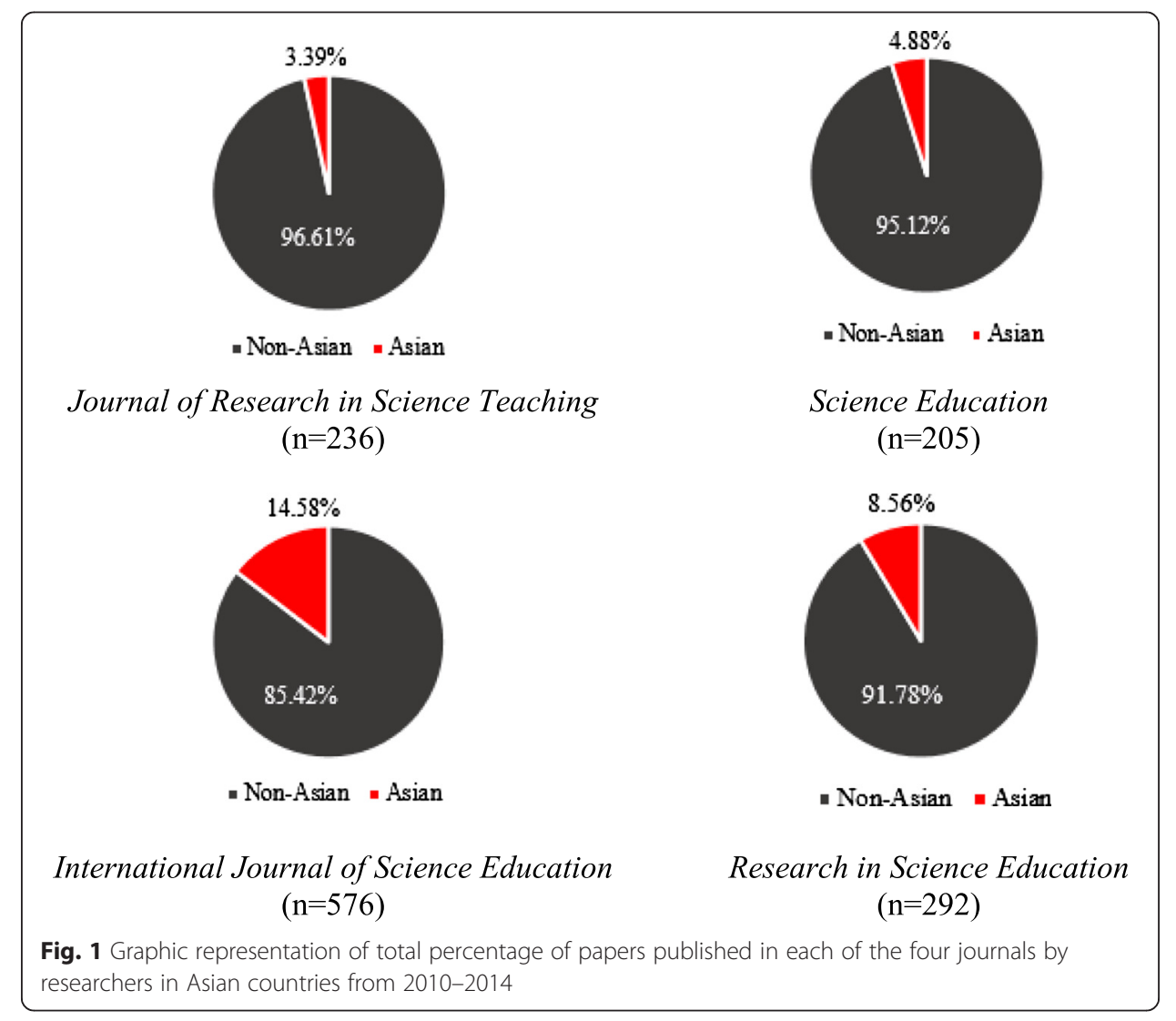


As has been discussed in a previous study examining publication trends in science education (Martin and Siry 2011), the patterns in publication are in part shaped by the sociohistorical development of these journals - with both JRST and SE being based in the United States and RISE and IJSE being based in Australia and the United Kingdom, respectively. These journals have long-established histories in their local contexts and three are associated with professional organizations whose members have traditionally published in these journals. For example, JRST is the flagship journal of the National Association for Research in Science Teaching (NARST) and the journal RISE is sponsored by the Australasian Science Education Research Association (ASERA) and while IJSE is not officially associated with the European Science Education Research Association (ESERA), members of this organization can receive a discounted subscription to the journal. As such, it is understandable that there may be fewer publications from researchers in Asian countries. Our intent with this author analysis is not to place the focus on these journals as being a "problem," but rather, we are offering this analysis to help us think about what research and whose research is currently being published in the top journals in science education and to raise some questions about how can we ensure that more research from institutions in Asian countries is also being made accessible in top international journals.

When we examine the publications in each journal, we see that only a small number of countries account for the total number of publications from countries in Asia (see Fig. 2),

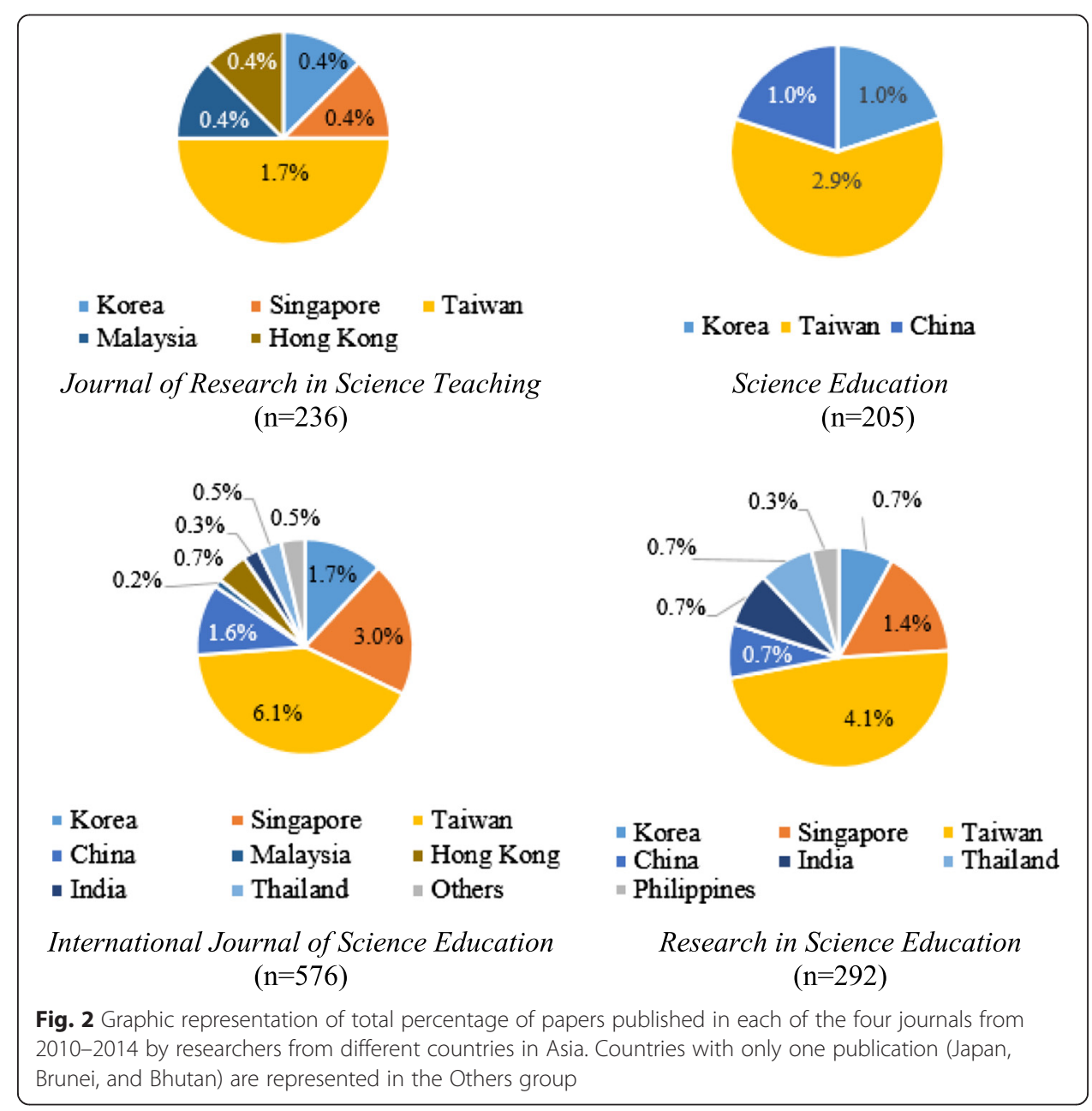


and within individual countries we found that many publications actually originated from a single institution or even a single author. We recognize that some countries have fewer universities and a limited number of science education faculty members, which can have an impact on how many manuscripts they can prepare and submit to international journals. In addition, we also recognize that many researchers may favor publishing in their own native-language journals so they may not have submitted many papers to these top journals. But some countries with long traditions of science education research, such as Japan, and countries that are currently developing their science education communities (Bhutan and Brunei) have only a single publication.

As such, both the innovations researchers and educators are developing and the challenges and issues facing the largest population of science teachers and learners in the world are missing from the international discourse that these journals represent. In addition to there being a lack of representation of research from Asian countries, our analysis also revealed that studies exploring science teaching and learning with participants from the Asian Diaspora are also rarely published in these top journals. Much of the science education research published has focused on understanding the science learning experiences of Asian students positioned as racial, cultural, and linguistic minorities. However, it is rare to find research studies that disaggregate data by ethnicity-instead researchers tend to use broad categories such as Asian or Pacific Islander as variables for describing differences in achievement or interest based on differences in race. Some studies exploring science teaching and learning in classrooms with students of the Asian Diaspora exist, but the experiences of these students and families are generally lumped together with other participants viewed as culturally or linguistically diverse. As a result, members of the Asian Diaspora are somewhat marginalized by scholars in educational research because they either failed to consider the need to study how different Asian students experience science and science learning or they have failed to recognize the value of exploring how the complex histories, cultures, and languages of individuals representing different ethnic groups may shape their experiences as science teachers and learners.

We hope that APSE can offer a space for researchers to voice the concerns of teachers, students, and families representing the Asian Diaspora. Today there is a growing call for research that seeks to examine and theorize about the experiences of members of the Asian Diaspora by raising questions about the intersections between race and ethnicity, drawing attention to the histories of intra-Asian colonialism and engaging in transnational discourse where scholars based in Asia and elsewhere can learn from one another (Wang 2012; Nakamura 2012; Martin 2010). Unfortunately, current global trends in academia suggest more scholars are competing to publish their work in a limited number of journals. Our analysis suggests that scholars seeking to disseminate research from Asia or focusing on participants who are Asian may have limited opportunities to publish their work. We believe APSE can offer researchers the space to engage in the kind of dialogue needed to raise awareness about how international and multi-discipline research can expand our individual and collective understanding about how science is being understood and experienced in local and global contexts. In doing so, we believe that the science education research community can gain insights from research published in 
our journal that can contribute to the development of more international and transnational research initiatives (Anderson-Levitt 2014).

\section{Impact of globalization on publishing in academia}

In this section, we describe some of the ways in which scholars in Asia have been affected by changes in academic publishing. The impact of globalization on higher education in Asia is evident in initiatives and educational reforms such as China's 211 project, Korea's BK21 program, Taiwan's Five Years Five Top university program, and Japan's National University of Administrative Cooperation (Chou 2014). Such reform efforts have resulted in the development of regulatory schemes for evaluating faculty research productivity. These schemes have had a significant impact on the culture of publishing in the fields of science and science education research as faculty in these areas are increasingly expected to publish in journals indexed in Thomson Reuters' ISI citation indexes, including the Science Citation Index (SCI) and the Social Science Citation Index (SSCI). Expectations from universities have contributed to growing pressures for researchers to publish their work in the specific indexed, high-impact journals that their universities have designated as necessary for promotion and tenure (Kao and Pao 2009). More recently, doctoral programs in countries like Korea and Taiwan have implemented policies requiring publication in international indexed journals as part of the requirements for conferring the doctorate degree to students who have already completed their research and written their dissertations. These changes are fueled in part by the need for universities to compete in global ranking systems measuring the relative quality and impact a faculty member's research has in the field (Curry and Lillis 2004).

Other forces driving these changes in publishing include requirements by funding agencies for scholars to publish findings from funded research in internationally indexed journals as part of the evaluation process of the impact of a project (Huang 2011; Lo 2010). As many universities and research funding agencies in different countries are partly regulated by government funding, individuals' and institutions' autonomy in whether or not to publish in internationally indexed journals becomes more and more limited. Alternatively, as more universities in Asian countries shift from federal governmental support toward privatization, pressure is mounting for these universities to become more highly ranked so they can attract more students and research funds to replace government funding (Rhoads and $\mathrm{Hu} 2012$ ).

In either case, the push towards internationalization of universities all around the globe means that researchers everywhere are finding themselves in greater competition to publish their work in the "places that count." Doing so has important implications for universities and institutions competing for funds, students, and faculty. Measuring faculty performance and productivity in terms of the number of publications in indexed journals has resulted in many researchers needing to sacrifice opportunities to publish in journals that are not internationally indexed (Flowerdew and Li 2009). Unfortunately, the vast majority of "high-impact" internationally indexed journals are currently published in English, which has had a negative impact on the quality and quantity of articles being submitted to local native language journals.

Currently, researchers in Asia face a variety of challenges that could have a negative impact on their ability to successfully publish their findings in a top-ranked education 
journal. The English language can be a barrier for scholars when writing papers, when searching for and reading published work, and when presenting findings at international conferences where other scholars (including journal editors and editorial board members) can learn about one's work. For many scholars in countries like China, Korea, Japan, and Vietnam, English is a foreign language and is generally used only in academic life. For other scholars, English may exist as a post-colonial legacy and may be used as part of academic or social life. This is true in countries like India, Singapore, or Hong Kong. In part because of these language barriers, there are perhaps fewer researchers from institutions in Asian countries serving as editorial board members for these top journals and there are fewer scholars serving as peer reviewers for these journals-which means fewer members of the Asian science education research community are in a position to represent the concerns of scholars from the region. While this is not necessarily problematic, a lack of representation by decision makers who are familiar with local research contexts, trends, and developments means that not only will papers written by non-native English speakers be reviewed by someone who may not appreciate the challenges the authors face as non-native English speakers, but they may also not be in the position to understand the value of the research in local contexts or may fail to recognize the social importance and the intellectual interest of research conducted in places about which they may have limited knowledge and understanding (Anderson-Levitt 2014).

Thus, we believe it is important for science education communities situated in Asian countries to seek representation in the on-going dialogues about how to improve science education and science education research in local and global contexts. In addition to seeking leadership positions in international organizations and on editorial boards of top journals in our field, we believe developing a new journal is an important way for scholars in the Asia-Pacific region to expand opportunities for sharing research across local contexts and to members of the international science education community. In the sections that follow, we describe how our decision to develop APSE as an OA journal offers our readers some alternatives to the current mainstream publication routes. Because this publishing model is still new, we provide some historical context for making sense of what OA is and how it works, and we describe how Springer and APSE are poised to support researchers in Asia to benefit from the OA publishing model to help us access studies more easily and with greater connectivity.

\section{The history of electronic publishing and electronic journals}

Twenty years ago, before academic research was widely available in electronic format, journal subscriptions were sold to academic libraries and individual researchers at a set subscription price. Generally the prices for individual subscription rates were much lower than institutional prices and often the subscription fee was associated with membership to a professional organization (Oppenheim 2008). However, as online editions of journals became more widely accessible, the business model for publishing and distribution of these materials changed dramatically (Wood 2005). Once content could be made widely accessible and easily shared, publishers needed to develop new pricing models to ensure continued demand for journals and profit for the companies. By "bundling" online subscriptions to entire catalogues of academic journals at prices significantly lower than the institutional subscription for each journal, academic libraries 
became compelled to enter contracts with large commercial publishing companies to provide faculty and students with access to content needed to support their research (Johnson 2005).

Known as "big deal" contracts, publishers sell electronic "site licenses" to libraries allowing access to specific IP addresses that ensure the rights to access journals that cannot be shared with others (Bergstrom et al. 2014). In this model, the bundle prices for institutions are no longer set-meaning the cost for access to content is negotiated with each institution (Poynder 2011). In addition, libraries contracting for the big deal do not need to store or maintain content physically, so they are able to offer thousands more titles than before-even if they are a small university or library. As a result, universities of all sizes have more access to content than before-including subscription access to rare titles that were previously not purchased because there were too few researchers to warrant the cost (Bergstrom, et al. 2014). While it can be argued that this model has expanded access to content for researchers in some universities, this practice has also had a negative impact on other libraries, professional organizations, and researchers who primarily published in or accessed content from journals sold by smaller or midsized publishing companies.

The prices libraries are asked to pay for bundled and non-bundled content has risen steadily over the last decade (White and Creaser 2007) - resulting in what some researchers refer to as a "serial crisis." This term has been used to describe the yearly increase of the cost of serial publications (such as magazines or journals). These prices restrict libraries from being able to offer full access to electronic as well as for other traditional media, including texts used in the humanities and social sciences that are not offered by the larger commercial companies. For libraries in developing countries, the serial increase in subscription prices means faculty and staff may not be able to access the most recent research. In addition, libraries have sacrificed subscriptions to journals published by small professional organizations, which has had a negative impact on studies conducted on topics that have traditionally had less support, such as gender studies or equity-related research. Reduction in institutional journal subscriptions for these organizations means less revenue to support academic conferences and a greater onus on individuals to purchase individual journal subscriptions for the titles where they have traditionally shared their work. Many of these smaller publishers and selfpublished professional societies have been purchased by larger commercial publishers because they were unable to cover the cost of developing and maintaining the necessary online repositories or for hiring the staff needed to oversee these changes (Marks and Janke 2009). The situation is even worse in the developing world, where journal subscription prices mean that many institutions simply cannot afford access to up-to-date research. The movement towards OA developed largely as a result of these issues. In the section that follows, we provide more detail about what OA is and how it affects scholars.

Open access publishing is considered to be both a business model and a social movement. There are two basic types, including green OA and gold OA. The first refers to the practice of self-archiving by placing a pre-published version of a manuscript in an online repository that is accessible to anyone. Gold OA means the final published version of the work can be made freely available to all users, usually for a fee paid to the publisher. Today, many researchers choose to self-archive a pre-print green OA version 
of their paper on their department website or personal webpage or even on popular social networking sites for academics, such as Academia.edu (www.academia.edu) or ResearchGate (www.researchgate.net). Manuscripts that are self-archived can be identical to the final version of a manuscript that has been accepted for publication by a journal or book publisher. However, the version that is made available to the public cannot be the final proof version or final published version of the paper. Sometimes these papers are called un-refereed pre-prints or working papers in advance of publication. Different publishing companies have different policies regarding self-archiving. SHERPA/ $\mathrm{RoMEO}^{2}$ offers users a searchable database where researchers can determine the policies different peer-reviewed journals have regarding the self-archiving of accepted articles on the web and in other OA repositories.

\section{Expanding opportunity through OA publishing}

In line with Springer's policy regarding new journals, APSE is being established as an online journal with OA publications. By making APSE an OA journal, all of our publications are freely available to read as text or to download as PDFs at any time. This means that university libraries can make APSE content available for free through the library catalogue, which can provide easy access for researchers, faculty, and students at any university. But even more importantly, because APSE is an OA journal, any user in the world with an Internet connection can access our journal content for free. As OA publishing is still relatively new and not well known for all researchers, we will spend some time in this article to share some information about the relative pros and cons of OA publishing for APSE authors and readers. ${ }^{3}$

\section{APSE is gold}

Because our journal uses a paid open-access model, it is a gold OA journal. Before entering the peer-review process, the author agrees to pay an article process charge (APC) to Springer to publish the paper and to give authors full rights to their own published work. Springer uses this fee to permanently archive the data on the APSE server so it can be accessible in the future as well. This means that once a paper passes through peer-review, the paper will be accessible to anyone and authors can freely share the final published version of all APSE papers using any media without any penalty or limitations. This is a clear benefit for researchers who want to disseminate their research to peers without fear of breaching copyright laws that bind traditional print journals. This process can have significant advantages for funding agencies that want to make findings of studies they funded available to the public. As a result, many funders provide money for researchers to make their findings available to the widest audience. Authors have several other funding options to support OA fees, including a Springersponsored fee waiver for researchers in countries classified as low-income or lowermiddle income economies, ${ }^{4}$ and APSE also offers some discounts and fee waivers for researchers who are current members of the KASE organization. ${ }^{5}$

Improving accessibility and visibility of research

Because APSE is an OA journal, our production model is designed to continually accept manuscripts for the review process, meaning there are no deadlines to meet 
to be considered for monthly issues. Instead, once a manuscript has gone through the peer-review process and a paper has been accepted for publication, the paper will be assigned a DOI number and the final electronic version will be available online to access and to share. In addition to archiving your data, the fees paid to Springer help to support electronic citation tracking and inclusion in bibliographic databases, which allow other researchers to easily locate and access your research using a variety of search engines and databases. Currently, Springer is the second largest publisher of academic journals and is the largest publisher of OA journals worldwide, so APSE authors will be well supported in sharing their research with a wide audience. A recent analysis by Springer of readership for their new OA journals found that the geographic distribution of readers is more diversified than for their traditional subscription journals. While many factors can influence citations for published work, researchers suggest that wide distribution and easy access may lead to a citation advantage for researchers who publish in OA journals (Norris et al. 2008; Atchison and Bull 2015).

One method publishers can use to help researchers to distribute their work more effectively is CrossRef, which is a service that allows readers to click on a reference citation in a journal and access the cited article. This is made possible by linking citations to CrossRef Digital Object Identifiers (CrossRef DOI) ${ }^{6}$ that have been referenced in various citation index systems. While many scholars are aware of the internationally used Science Citation Index (SCI) and Social Science Citation Index (SSCI) systems developed by Thomson Reuters, many countries in Asia have also developed their own domestic citation index systems (Chou 2014). For example, Taiwan has the Taiwanese Science Citation Index (TSCI) and Korea has the Korean Citation Index (KCI). The purpose of these databases is to provide scholars a way of tracking the quantity of submissions to journals and to measure the impact and quality of publications in local journals. The development of index systems like TSCI and KCI can benefit scholars who cite articles in APSE that have been referenced in these systems. For example, APSE readers will be able to connect to articles linked by CrossRef that have been published in native-language journals. In addition, because highly indexed journals tend to offer English language abstracts for each article, Springer can support APSE readers to connect directly to the primary source articles to read English-language abstracts or to access native-language articles. Since competition for Taiwanese and Korean scholars to publish in highly ranked journals in the TSCI and KCI databases has increased and researchers are under considerable pressure to publish in a narrowing field of sanctioned journals (Chou 2014), the connectivity of these systems means more research is accessible than ever before.

For scholars who routinely publish in non-English language books and journals and who need to translate their name from a native language to English, it is important to consistently write the names of people and journals so cross-referencing systems can correctly attribute work to the right scholars and journals. At APSE we recommend that authors determine how they want to abbreviate their names (for example, Chu, H.E., or Chu, H.-E., or Chu, H.) and that they consistently use the same method in all of their publications. Authors may also choose to register with ORCID, ${ }^{7}$ a service that provides a digital identifier to help authors distinguish themselves from other researchers with the same name or initials. In addition, we ask that materials referenced 
from non-English language journals, books, reports, or websites use an English language citation, if provided, or, for translated information, a footnote to inform the reader about the method used to transliterate the citation into English. ${ }^{8}$ For example, Korean can be transliterated into English by using two different systems, Revised Romanization or McCune-Reischauer. If a researcher does not define the system used to transliterate Korean to English, readers will be limited in their ability to access additional information about the topic in native language resources. By providing this kind of information to APSE readers, we can help scholars easily access, cite, and share research from native-language journals, which can also increase the likelihood that research published in APSE can have a positive impact on the field of science education in both local and international contexts. In the sections that follow, we offer some practical details about the peer review process and features that make our journal unique when compared to existing science education journals.

\section{The scope and vision for APSE}

APSE publishes original articles examining on-going educational problems associated with science learning and teaching. The journal's scope is broad in both methodology and content. We accept research conducted at all levels, including early childhood, primary, secondary, tertiary, workplace, and informal learning, as they relate to science education. We invite scholarly manuscripts employing various methodological approaches, including qualitative as well as quantitative research designs and mixed-methods studies. APSE also publishes theoretical papers, position papers, and critical reviews of literature on emerging issues in the field of science education.

A central goal for APSE is to help support future generations of science education scholars in the Asia-Pacific region. In addition to supporting early career scholars, we also offer a home for established researchers who wish to continue building strong foundations for science education research by publishing articles appreciated by both regional and international audiences. We hope that APSE will offer all generations of researchers a collective space for sharing work that contextualizes some of unique issues faced by science educators, researchers, teachers, and students in the Asia-Pacific region. Specifically, we encourage authors writing for APSE to provide more detail about the context in which their studies were conducted, and we ask that authors discuss how their findings are salient in these local contexts, as well as in regional (Asia) and international contexts. We also want to encourage researchers outside of Asia who are exploring issues faced by members of the Asian Diaspora to share their work in APSE. In doing so, APSE seeks to offer readers a more contextualized understanding of the ways in which Asian teachers, students, and families living in communities outside of the AsiaPacific region experience science teaching and learning.

\section{APSE peer review process and English-language editorial supports}

In this section, we describe some of the unique features APSE offers our authors and readers, including a supportive peer-review process that is more considerate of the challenges faced by non-native English speakers. Our journal uses a double- 
blind review process to ensure we publish high quality research, but we also work hard to support authors to first make it to the peer review process (See Fig. 3). Many non-native English speakers who have submitted their papers to English language journals fail to have their papers reviewed at all because their papers are rejected by journal Editors prior to review (sometimes referred to as a desk reject or reject before review). At APSE, we offer several options for scholars-including editor's review before peer review. This is because APSE editors and editorial board members are aware of the challenges facing non-native English speaking authors and we are aware of the discrimination that researchers face when using nonstandard forms of English.

A primary goal of our journal is to make sure that our readers have the chance to have their work reviewed and to receive substantive feedback about their research. Thus, when papers are received that need considerable revision before being sent out for peer review, the editors will elect to have authors revise the paper before review-which means the paper will not automatically be rejected as is often the case for other journals. Instead, the editors will provide salient feedback about how to improve the quality of the study, and the editor may also invite the author to engage in a video chat to discuss the details of the paper in order to gain more insight into the purpose of the study. From this dialogue, the editor can offer suggestions to help the author revise and resubmit their work for review. In addition,

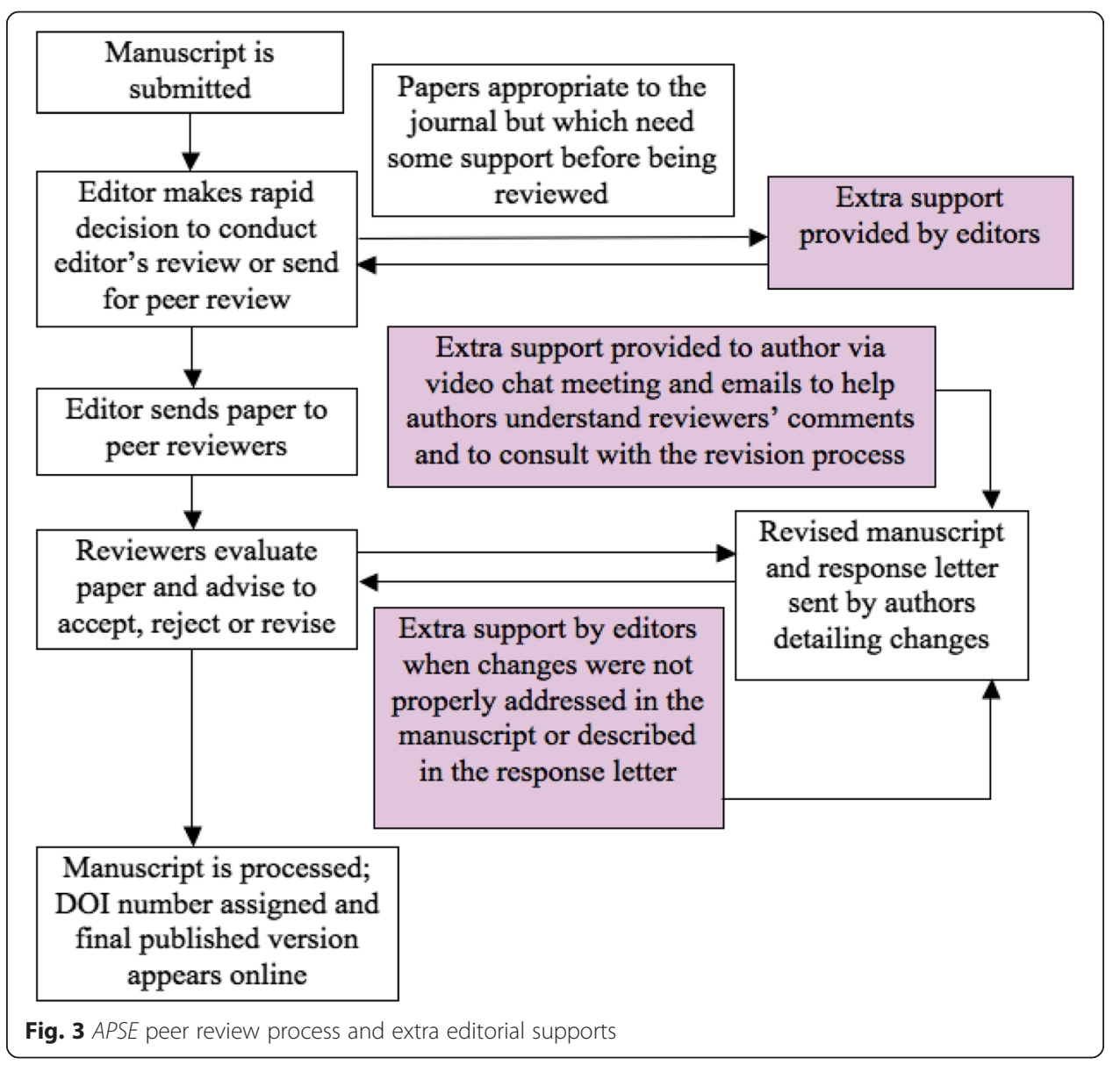


the editors can suggest affordable and trusted English-language editing services to help the author improve the quality of the writing.

Once the paper has been improved and is resubmitted, the editors will send the paper for review. At this stage, we ask our editorial board members to offer specific support and recommendations for improving the quality of the study without focusing too much attention on English-language problems. We ask peer reviewers to consider the goals of APSE and to work to see the value of the research by first looking beyond potential language issues. The goal here is to make sure that scholars receive feedback that can enhance their research even if the manuscript has Englishlanguage problems. Very often scholars receive instant rejection notices, so they never have any opportunity to benefit from peer review (Wellington and Nixon 2005). We believe this process is especially helpful for graduate students and junior scholars.

At APSE, we hope to have our editorial board members engage in a peer-review dialogue with authors that enhances the review process for the author and that provides the reviewer a chance to mentor a colleague in their research and writing. To do this, APSE Editors have worked hard to identify scholars in different countries in the region and internationally to serve as peer-reviewers. As the APSE readership grows, we will continue to network with scholars throughout the region to invite them to become part of our editorial board. At APSE we have a commitment to establishing a peer-review process that is both rigorous and supportive and we believe that having representatives from science education communities in the region is an important part of making this possible. We do not want the peerreview process to serve as a means of excluding the voices of researchers who may struggle to express themselves clearly in English. Instead, we hope to use the peerreview process as a means of strengthening our research community while also disseminating top-quality research.

To help meet this goal, editors at APSE will provide authors decision letters with explicit details for how to revise their paper for publication. During the revision process, we also offer online consultations (via email or video chat) to discuss decision letters with authors who may be unsure about how to meet the requested changes. In addition, because APSE is committed to providing researchers in the region an opportunity to be involved in shaping the kinds of research that is disseminated in the journal, we invite scholars to serve as guest editors by proposing special issues about topics of interest in individual countries and in the region. Guest editors will be supported by APSE to manage the call for papers about a special issue and to manage the review and publication process. By providing a space for scholars to communicate about important topical concerns, we hope our readers will develop a sense of ownership for the journal that fosters a strong sense of community among researchers in the region.

Finally, because APSE is committed to supporting research in local and international contexts, our journal provides authors the opportunity to write an executive summary of their accepted article in their native language that will also be made available to readers through our journal website. The executive summaries can range in length from 5001,000 words and should provide the title, overview of main findings, and keywords in the author's native language. The purpose of the native-language summary is to allow researchers to share their work with scholars and teachers in their local contexts even while 
publishing an article in English. We are aware that the when authors publish their work in English it can mean that teachers and policy makers may not benefit from their findings. By offering the native-language executive summary, APSE hopes researchers can share their work with the international research community without sacrificing opportunities for stakeholders in local contexts to learn about their work.

\section{APSE: overview of the first issue}

With collaborative research efforts exploring issues in Asia and with students of the Asian Diaspora in six different countries, this first issue reflects the diversity of research we seek to publish in APSE. The authors draw on different theoretical frameworks and employ both qualitative and quantitative research methods to address issues in science education in Asia or with participants representing the Asian Diaspora who live outside of the geographical region.

Drawing from ethnographic data, Ryu (2015) examines how a Korean transnational girl's identity construction was influenced by meso-level contexts (e.g., school, classroom) and personal contexts (e.g., gireogi family contexts) while learning science in an advanced placement (AP) biology class in the United States. This study offers implications about the need for researchers and teachers to pay attention to students' individual differences and contexts in order to better facilitate their science learning and classroom participation. This study also highlights the need for educators and researchers in sending and receiving countries to learn more about the impact of transnational educational migration on Asian students and their families.

In their discussion of the challenges facing gifted science education in the Philippines, Larroder and Ogawa (2015) provide some insights into the need for valid and reliable instruments that can be used to identify science-gifted students while also accounting for how giftedness is socially constructed in the Philippines. Their paper reports the validity and reliability of an adapted 60-item checklist on science giftedness used with students in four different science-gifted programs. The researchers found significant differences in the range of scores and discuss the need for additional research design tools that are both domain specific and holistic enough to assess other facets of giftedness.

Fulmer et al. (2015) share findings from a study using two-tier multiple-choice (TTMC) items to assess students' knowledge of a scientific concept and their reasoning about this concept. Employing a Rasch measurement model on TTMC items, the researchers explored whether items were distinguishable according to different traits, different content sub-topics within the instrument, or both content and tier. Data from Singapore and Korea was analyzed and researchers concluded that TTMC items cannot be assumed to have a consistent pattern of difficulty by tier and that assessment developers and users need to consider how the tiers operate when administering TTMC items and interpreting results. Researchers offer implications for implementing this model of analysis in Asian contexts.

Tobin (2015) offers a description of how his research has evolved to include studies of science for literate citizenry while aiming to transform the experiences of teachers and learners. Specifically, he explores how the incorporation of Jin Shin 
Jyutsu, a complementary medical knowledge system, can help teachers and learners to ameliorate intense emotions, become mindful, and improve their health and well-being. He discusses how multilogical methodology, polysemia, subjectivity, and polyphonia can be employed to preserve the integrity and potential of knowledge systems that can help to generate and maintain disparate perspectives, outcomes, and implications for practice. He concludes his paper by raising questions about the need for science educators to address grand challenges that threaten the Earth and its social institutions before it is too late.

\section{Invitation to change the future of science education}

We hope that the range of contexts and topics explored in this first issue will inspire researchers, teacher education professionals, and teacher practitioners to submit innovative papers that initiate dialogue about important issues in science education while also informing educational theory and methodology, both locally and internationally. We conclude this editorial with an invitation for all science education researchers who are interested in sharing work from the region and from studies involving teachers, students, and families of the Asian Diaspora to submit their manuscript to APSE. In doing so, we hope that our journal will grow to become a central channel for researchers who want to learn about issues facing a group of science teachers and learners who have not been well represented in the current publication outlets.

\section{Endnotes}

${ }^{1}$ The term "Asian Diaspora" refers to emigrants from Asian countries and their descendants who live "outside the country of their birth or ancestry, either on a temporary or permanent basis, yet still maintain affective and material ties to their countries of origin" (p. 2, Agunias and Newland 2012).

${ }^{2}$ You can learn more about this database by visiting http://www.sherpa.ac.uk/ romeo/

${ }^{3}$ To learn more about open access policies at Springer, please visit http://academy.springer.com/open-access

${ }^{4}$ You can learn which countries qualify for an automatic waiver for authors by visiting http://www.springeropen.com/authors/oawaiverfund/

${ }^{5}$ Benefit applies to current members of KASE. To learn more about how to become a member and what benefits are offered, please visit http://www.koreascience.org/ english/

${ }^{6}$ To learn more about CrossRef and to find out what journals and publishers are indexed in this database, please visit http://www.crossref.org/

${ }^{7}$ To learn more about ORCID or to register for your own unique identifier please visit http://orcid.org

${ }^{8}$ For more detailed information about how to cite non-conventional names and examples of how to cite sources for transliterating other languages into English, please visit the APSE website (www.apse-journal.com). 
PA, where she conducted studies examining the intersections of gender, ethnicity, and language learning in science classrooms. During this research, she became interested in the science education experiences of students who had recently immigrated to the US from Asian countries. To learn more about science education in Asia, Sonya accepted an international faculty position at Seoul National University and moved to Korea in 2011, where she is learning Korean and is actively engaging in collaborative research with colleagues in Asia. Currently she is $\mathrm{PI}$ of a project examining the challenges of schools and teachers serving multicultural students in Korean science classrooms and she is co-PI on a project examining the impact of Confucian ideology on interactions and discourse in science classrooms in Korea, China, Hong Kong, Japan, and Taiwan. She serves as an editorial board member for several journals, including the Journal of Research in Science Teaching, Research in Science Education, Journal of Science Teacher Education, Cultural Studies of Science Education, and EURASIA Journal.

2. Hye-Eun Chu is a lecturer at the School of Education at Macquarie University in Sydney, Australia. Hye-Eun's research interests lie in the areas of conceptual development in science learners, interdisciplinary approaches in science (e.g., environmental education, STEM education, and multicultural education), affective factors in the science classroom, evaluation of pedagogical approaches, and diagnostic/formative assessment. Prior to joining Macquarie University, she was an assistant professor at the National Institute of Education (NIE), Nanyang Technological University in Singapore. Before joining in NIE, she spent three years as a postdoctoral research fellow working with Professor David Treagust at the Science and Mathematics Education Centre (SMEC) of Curtin University of Technology in Perth where her research was funded by grants from Dankook University in Korea and the Korean Research Foundation. She is serving as a co-editor of the Asia-Pacific Science Education Journal and editorial board member of the International Journal of Science and Mathematics Education.

\section{Author details}

${ }^{1}$ Earth Science Education Department, College of Education, Seoul National University, Seoul, Republic of Korea. ${ }^{2}$ School of Education, Macquarie University, Sydney, NSW 2109, Australia.

Received: 19 November 2015 Accepted: 19 November 2015

Published online: 21 December 2015

\section{References}

Agunias, D. R., \& Newland, K. (2012). Developing a Road Map for Engaging Diasporas in Development: A Handbook for Policymakers and Practitioners in Home and Host Countries. Geneva and Washington: International Organization for Migration and Migration Policy Institute. http://www.gfmd.org/pfp/policy-tools/diaspora-handbook - Accessed on 10 August 2015.

Anderson-Levitt, K. M. (2014). Significance: recognizing the value of research across national and linguistic boundaries. Asia Pacific Educational Review, 15, 347-354. doi:10.1007/s12564-014-9322-0.

Atchison, A., \& Bull, J. (2015). Will Open Access Get Me Cited? An Analysis of the Efficacy of Open Access Publishing in Political Science. PS Political Science \& Politics, 48, 129-137.

Bergstrom, T. C., Courant, P. N., McAfee, R. P., \& Williams, M. A. (2014). Evaluating big deal journal bundles. Proceedings of the National Academy of Sciences of the United States of America, 111(26), 9425-9430. http://doi.org/10.1073/pnas. 1403006111.

Chou, C. P. (2014). The SSCI Syndrome in Higher Education: A Local or Global Phenomenon. Taipei: Sense Publishers.

Curry, M. J., \& Lillis, T. (2004). Multilingual scholars and the imperative to publish in English: Negotiating interests, demands, and rewards. TESOL Quarterly, 38(4), 663-687.

Flowerdew, J., \& Li, Y. (2009). English or Chinese? The trade-off between local and international publication among Chinese academics in the humanities and social sciences. Journal of Second Language Writing, 18(1), 1-16.

Fulmer, G.W., Chu, H.-E., Treagust, D.F., \& Knut, N. (2015). Is it harder to know or to reason? Analyzing two-tier science assessment items using the Rasch measurement model. Asia-Pacific Science Education.

Huang, J. C. (2011). Attitudes of Taiwanese scholars toward English and Chinese as languages of publication. Asia Pacific Journal of Education, 31(2), 115-128. doi:10.1080/02188791.2011.566983.

Johnson, R. K. (2005). Open Access. Journal of Library Administration, 42(2), 107-124. doi:10.1300/J111v42n02_08.

Journal Citation Reports ${ }^{\circledast}$. (2014). Thomson Reuters.

Kao, C., \& Pao, H. L. (2009). An evaluation of research performance in management of 168 Taiwan universities. Scientometircs, 78(2), 261-277. doi:10.1007/s11192-007-1906-6.

Larroder, A. \& Ogawa, M. (2015). The development of a self-evaluation checklist for measuring Filipino students' science giftedness. Asia-Pacific Science Education.

Lee, M-H, Wu, Y-T., \& Tsai, C-C. (2009). Research trends in science education from 2003-2007: A content analysis of publications in selected journals. International Journal of Science Education, 15(1), 1999-2020.

Lo, W. Y. W. (2010). Decentralization of higher education and its implications for educational autonomy in Taiwan. Asia Pacific Journal of Education, 30(2), 127-139.

Marks, J., \& Janke, R. A. (2009). The Future of Academic Publishing: A View From the Top. Journal of Library Administration, 49(4), 439-458. doi:10.1080/01930820902832579.

Martin, S. (2010). "Act locally, publish globally": International/multi-disciplinary research efforts needed to understand the impact of globalization on science education. Cultural Studies of Science Education, 5(2), 263-273.

Martin, S., \& Siry, C. (2011). Networks of practice in science education research: A global context. Journal of Research in Science Teaching, 48(6), 592-623.

Nakamura, R. (2012). What Asian American studies can learn from Asia?: towards a project of comparative minority studies. Inter-Asia Cultural Studies, 13(2), 251-266. doi:10.1080/14649373.2012.659812.

Norris, M., Oppenheim, C., \& Rowland, F. (2008). The citation advantage of open-access articles. Journal of the American Society for Information Science, 59, 1963-1972. doi:10.1002/asi.20898.

Oppenheim, C. (2008). Electronic scholarly publishing and open access. Journal of Information Science, 34(4), 577-590. 
Park, S.-J. (1996). Retrospective and prospect of grown-up KASE. Journal of the Korean Association for Science Education, 16(4), 486-490

Poynder, R. (2011). The big deal: Not price but cost. Information Today, 28(8). Retrieved on September 23, 2015 from www.infotoday.com/it/sep11/The-Big-Deal-Not-Price-But-Cost.shtml

Rhoads, R. A., \& Hu, J. (2012). The internationalization of faculty life in China. Asia Pacific Journal of Education 32(3), 351-365. doi:10.1080/02188791.2012.711293.

Rollnick, M., Adler, J., \& Setati, M. (2009). The institutional location of research in Mathematics and Science Education in South Africa. African Journal of Research in MST Education, 13(1), 115-130.

Ryu, M. (2015). An examination of Melody's identities, contexts, and learning in a US science classroom: implications for science education of Asian transnational students. Asia-Pacific Science Education.

Song, J., \& Joung, Y. J. (2014). Trends in HPS/NOS Research in Korean Science Education. In M. Matthews (Ed.), International Handbook of Research in History, Philosophy, and Science Teaching (pp. 2176-2216). Dordrecht: Springer.

Tsai, C-C. (2005). Research and trends in science education from 1998 to 2002: A content analysis of publication in selected journals. International Journal of Science Education, 27(1), 3-14.

Tobin, K. (2015). Connecting science education to a world in crisis. Asia-Pacific Science Education.

Wang, C. M. (2012). Editorial introduction: between nations and across the ocean. Inter-Asia Cultural Studies, 13(2), 165-175. doi:10.1080/14649373.2012.659806.

Wellington, J., \& Nixon, J. (2005). Shaping the field: the role of academic journal editors in the construction of education as a field of study. British Journal of Sociology of Education, 26(5), 643-655. doi:10.1080/01425690500293835.

White, S., \& Creaser, C. (2007). Trends in Scholarly Journal Prices 2000-2006. Loughborough: Oxford University Press.

Wood, E. H. (2005). Open Access Publishing. Journal of Electronic Resources in Medical Libraries, 2(2), 1-12. doi:10.1300/ J383v02n02_01.

Submit your manuscript to a SpringerOpen ${ }^{\circ}$ journal and benefit from:

- Convenient online submission

- Rigorous peer review

- Immediate publication on acceptance

- Open access: articles freely available online

- High visibility within the field

- Retaining the copyright to your article

Submit your next manuscript at $>$ springeropen.com 